DOI: http://doi.org/10.21698/simi.2018.fp26

\title{
ENVIRONMENTAL ISSUES RESULTING FROM THE EXCAVATION OF ALLUVIAL SOIL IN PROTECTED AREAS, CASE STUDY IN ROSCI 0103 LUNCA BUZAULUI
}

Giuliano Tevi ${ }^{1}, \underline{\text { Alexandra Stoica }^{2}}$

${ }^{1}$ Ecological University of Bucharest, 1G Vasile Milea Blvd., Bucharest, giuliano.tevi@ueb.ro, Romania

${ }^{2}$ University of Bucharest, 6 Traian Vuia, Bucharest, nicoleta.alexandra.stoica@gmail.com, Romania

\begin{abstract}
The current study tackles the issue of excavating alluvial deposits in protected areas included in the Natura 2000 network, which was expanded in 2016 to 23\% of Romania's territory. A significant percent of the Natura 2000 areas in Romania directly target or are connected to fluvial elements where machinery for alluvial deposits is used. The Natura 2000 ROSCI 0103 Lunca Buzaului following along the Buzau River had an initial length of $110 \mathrm{~km}$ and a surface of $6987 \mathrm{ha}$; subsequent to the 2016 expansion it now has a length of $140 \mathrm{~km}$ and a surface of $9575 \mathrm{ha}$. In the studied area there are 62 perimeters leased for exploitation with a total area of 594.39 ha (6.2\% of the site surface). For data analysis and management both GIS techniques and specific methods for interpreting remote sensing data were used. For this study, the following resources are used: Pleiades panchromatic and multispectral images at 0.5 and $2 \mathrm{~m}$ spatial resolution, orthophotos at $2.5 \mathrm{~m}$ spatial resolution, Digital Terrain Model (DTM) based on a 20m network. Thematic vectors: ROSCI 0103 limits, road network, geology. Data is processed and interpreted using specific software - ENVI EX for remote sensing data processing and QGIS for the development of the GIS database.

Following the assessment, maps were drawn up highlighting the details of exploitations, the risk elements associated with the spatial-temporal evolution.

These are key elements in the process of assessing the environmental impact and the risk for the population in affected areas.
\end{abstract}

Keywords: environmental impact, GIS, Natura 2000, NDVI, remote sensing

\section{Introduction}

The Natura 2000 network was established in Romania in 2007 when 273 sites of community importance (SCI) and 108 special protection areas (SPA) were designated by MO no. 1964/2007 and GD no. 1284/2007, covering $17.84 \%$ of Romania's territory. In 2011 and 2016 the Natura 2000 network was expanded to $23 \%$ of Romania's territory. 


\section{INTERNATIONAL SYMPOSIUM "THE ENVIRONMENT AND THE INDUSTRY", SIMI 2018, PROCEEDINGS BOOK}

A significant percent of the Natura 2000 areas in Romania directly target or are connected to fluvial elements where machinery for alluvial deposits is used. The process of gravel pit excavation expanded over time, as population increased and the need of aggregates (usually comprising sand and gravel) had to meet up with the development of the infrastructure construction. Gravel pit is a term used in civil engineering that refers to small scale quarries or excavations, usually close to water streams and roads. Aggregate extraction is becoming an environmental issue as the demand of construction materials follows a rising trend. Improper extraction and restoration practices affect wide areas and can lead to vegetation clearing, soil erosion, landslides, modification of the natural drainage, displacement of species and habitats etc.

The Natura 2000 ROSCI 0103 Lunca Buzaului following along the Buzau River had an initial length of $110 \mathrm{~km}$ and a surface of 6987 ha; subsequent to the 2016 expansion it now has a length of $140 \mathrm{~km}$ and a surface of 9575 ha. The protected area is located in two counties, Buzau and Braila (Figure 1), crossing three biogeographical regions - Alpine 0.54\%, Continental 24.20\%, and Steppe $75.27 \%$.

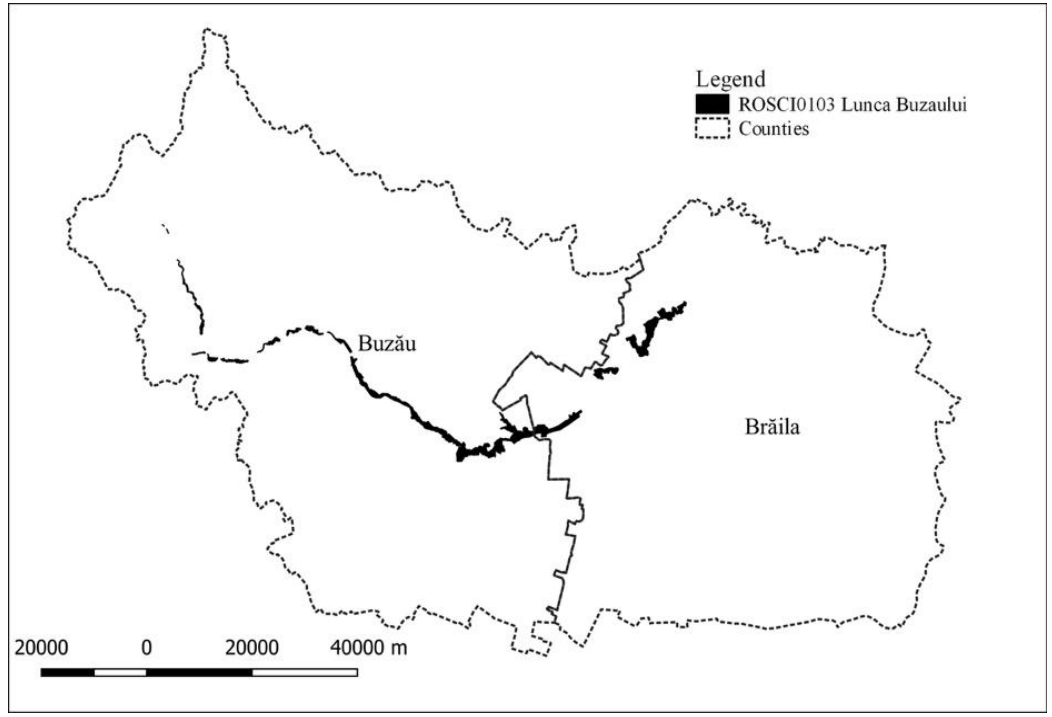

Figure 1. Position of the ROSCI 0103 Lunca Buzaului protected area

The conservation objectives considered for the designation of the ROSCI 0103 Lunca Buzaului are the following: (Natura 2000, 2016):

Habitats - 1530 Pannonic salt steppes and salt marshes; 3130 Oligotrophic to mesotrophic standing waters with vegetation of the Littorelletea uniflorae and/or of the Isoëto-Nanojuncetea; 3240 Alpine rivers and their ligneous vegetation with Salix 


\section{INTERNATIONAL SYMPOSIUM "THE ENVIRONMENT AND THE INDUSTRY", SIMI 2018, PROCEEDINGS BOOK}

elaeagnos; 62C0 Ponto-Sarmatic steppes; 6430 Hydrophilous tall herb fringe communities of plains and of the montane to alpine levels; 91E0 Alluvial forests with Alnus glutinosa and Fraxinus excelsior (Alno-Padion, Alnion incanae, Salicion albae); 91F0 Riparian mixed forests of Quercus robur, Ulmus laevis and Ulmus minor, Fraxinus excelsior or Fraxinus angustifolia, along the great rivers (Ulmenion minoris); 92A0 Salix alba and Populus alba galleries; 92D0 Southern riparian galleries and thickets (Nerio-Tamaricetea and Securinegion tinctoriae) and species Lutra lutra, Spermophilus citellus, Bombina bombina, Bombina variegata, Emys orbicularis, Triturus dobrogicus, Barbus meridionalis, Cobitis taenia, Gobio kessleri, Gobio uranoscopus, Callimorpha quadripunctaria, Cerambyx cerdo, Lycaena dispar, Agrimonia pilosa and Eleocharis carniolica.

The protected area was designated for the conservation of aquatic and riparian habitats, as well as of some plant species, invertebrates, amphibians, reptiles and mammals. The life conditions for all these species are characterized by the presence and quality of water.

In the studied area there are 62 perimeters leased for aggregate extraction (Figure 2) with a total area of 594.39 ha (6.2\% of the site surface).

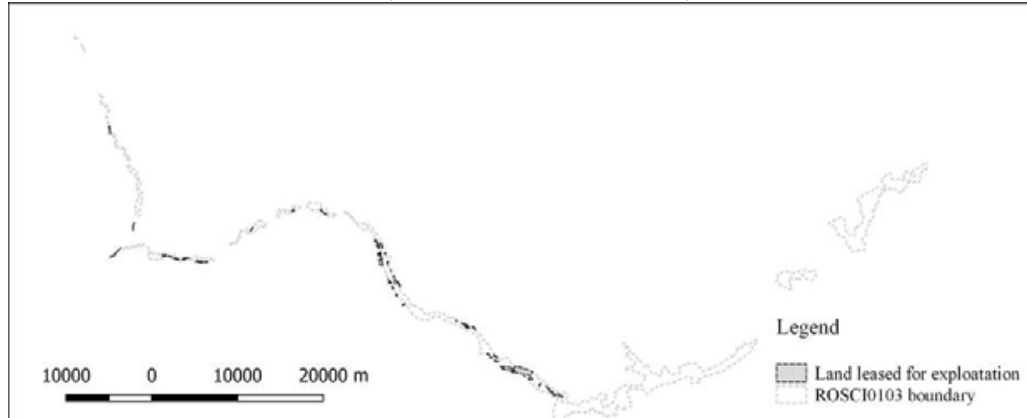

Figure 2. Locations of perimeters leased for aggregate extraction

The application of an effective management in protected areas requires a strict assessment as basis for the decision-making process regarding the permitting of any economic activity. The large number of effects generated by the works executed in the meadow area or directly in the river bed determines the use of some spatial analysis instruments for assessing the river flow processes, the sediment accretion rate and the management of infrastructure logistics components.

\section{Materials and Methods}

The impact assessment of the extraction and mining of useful minerals sometimes requires complex analyses of the mining perimeter location and access roads, 


\section{INTERNATIONAL SYMPOSIUM "THE ENVIRONMENT AND THE INDUSTRY", SIMI 2018, PROCEEDINGS BOOK}

correlated to the spatial distribution of protected elements, for which the protected status was granted.

These assessments of extended areas which are characterized by geological, pedological, topographic and even climatic variables require the storage and processing of large data volumes. The best solution is to use the GIS environment and remote sensing data. The accurate interpretation of these data sets requires several stages of field calibration and validation so as to ensure that results are representative under inevitable extrapolations.

For this study, the following software was used: QGIS 3.2 as GIS and ENVIEX instrument for processing remote sensing data. As base map layers data for the remote sensing data, images taken by the Pleiades satellite at $0.5 \mathrm{~m}$ (panchromatic) and $2 \mathrm{~m}$ (4 layers multispectral - RGB-Ir) spatial resolution were used, as well as 3 layers - RGB orthophotos with $2.5 \mathrm{~m}$ spatial resolutions. The different moments of the two data sets allow analyses of the processes' dynamics from a temporal perspective.

For the interpretation of the relief conditions and river area morphology on distinctive sectors, the Digital Terrain Model (DTM) based on a 20 m network was used.

The vector data used or developed throughout the study are: the limits of the ROSCI 0103 Lunca Buzaului protected area and those of perimeters leased for exploitation, provided by the environmental authorities, as well as infrastructure elements obtained by analyzing available OpenStreetMap data sets (http:// www.openstreetmap.org).

A common characteristic of the remote sensing data recorded for this type of landscape - river environment located in a hilly area, with an extended development of the water meadow area and terraces, and an increased density of localities and infrastructure elements, is represented by the high degree of spectral heterogeneity. In addition, there are also many natural or semi-natural habitats, characterized by various plant associations. This is why it was required to use an index allowing for a differentiated analysis and effective interpretation of available data. Due to the importance and spread of the vegetation elements inside the protected area, the authors chose to use the normalized difference vegetation index (NDVI), as this also allows for extended assessments of the nature of the substrate, exceeding the presence and consistency of the plant tissue and chlorophyll (Yengoh et al 2015).

The normalized difference vegetation index (NDVI) was initially designed and introduced for the interpretation of satellite imagery for various evaluations of the plant layer, the natural vegetation and various types of agricultural crops. This index is determined based on an empirical formula (1), representing the ratio of the difference between the near-infrared reflectance (NIR) and red and their sum.

$$
N D V I=N I R-R / N I R+R
$$

Section Pollution Assessment \& Management Systems 218 


\section{INTERNATIONAL SYMPOSIUM "THE ENVIRONMENT AND THE INDUSTRY", SIMI 2018, PROCEEDINGS BOOK}

NDVI values vary depending on the absorption of the radiation by chlorophyll in the red spectral region and its reflectance in the near infrared spectral region. The values may range from -1 to +1 , the positive values corresponding to plant coverings. The higher the chlorophyll content is, the higher the NDVI values, trending to 1.

In specialized studies substantiating the use of NDVI, its values are determined in relation to various land uses, such as Omran, EE using Landsat 5 imagery from 1984 and Landsat 7 imagery from 2011 (Omran 2012) to calculate NDVI values for several classes of land use (Table 1).

Table 1. NDVI by land-use type (Omran 2012)

\begin{tabular}{c|cc}
\hline Land-Use Classes & NDVI 1984 Image & NDVI 2011 Image \\
\hline Water & -0.3764 & -0.4357 \\
Waterlogged 1 & -0.1089 & -0.0813 \\
Waterlogged 2 & -0.3691 & -0.5697 \\
Vegetation & 0.5276 & 0.6546 \\
Barren Land & -0.0945 & -0.0864 \\
Build-up Land & -0.0291 & -0.0465 \\
\hline
\end{tabular}

In order to classify the land use from the ROSCI 0103 Lunca Buzaului protected area so as to assess the impact generated by the exploitation of alluvial material, the NDVI used was determined based on Pleiades multi-spectral 4-band satellite imagery (RGB-Ir), with a $2 \mathrm{~m}$ resolution. The data was recorded in July, during the maximum vegetation period.

By considering the taken imagery and the spatial distribution of the exploitation perimeters (Figure 2), region of interest (ROI) were set (Figure 3).

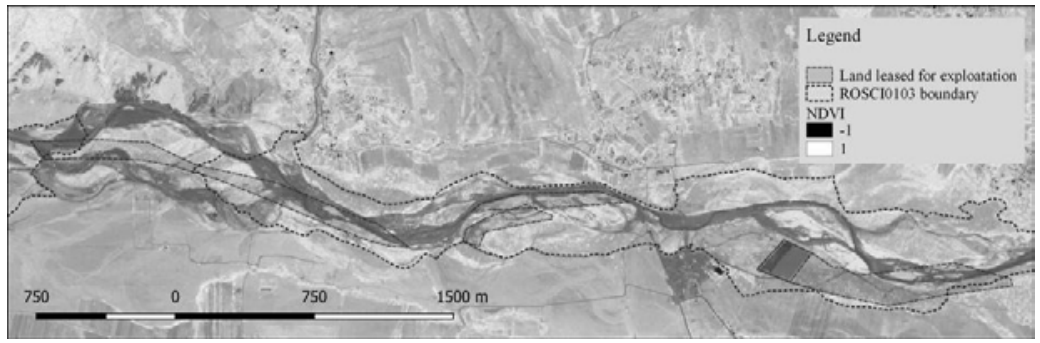

Figure 3. NDVI for ROI

After NDVI was determined for these regions, an assisted classification algorithm of obtained values was set and calibrated by correlating satellite imagery with field observations (Figure 4). 


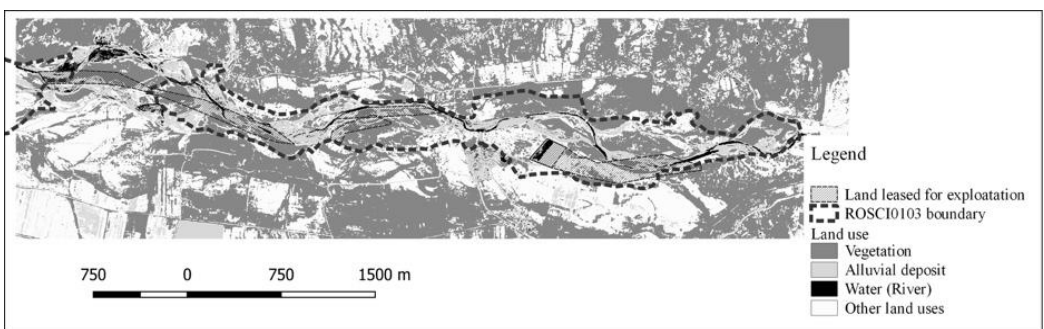

Figure 4. ROI with land use classes based on NDVI

Table 2 presents Land-Use classes in the study area based on Pleiades imagery.

Table 2. NDVI by land-use type in study area, based on Pleiades imagery

\begin{tabular}{c|cc}
\hline Land-Use Classes & NDVI min & NDVI max \\
\hline Water (River) & -0.30 & -0.20 \\
Alluvial deposit & -0.19 & 0.15 \\
Vegetation & 0.40 & 0.80 \\
\hline
\end{tabular}

Following the land use analysis and its correlation with the spatial distribution of perimeters leased for exploitation, two distinctive situations were identified, as regards the potential impact on habitats. A first class was defined for surfaces with low potential impact and another class includes surfaces with medium potential impact. The first class includes surfaces located close to the river bed and occupying areas of the natural deposition of alluvial material from the meanders of the minor bed; the second class corresponds to perimeters containing vegetation; it was concluded that the exploitation in this area generates an impact on the protected habitats. This classification also considered the risk of erosion associated with the exploitation of alluvial material in certain areas specific to the river bed. In the first class were also included perimeters located outside the limits of the protected area (Figure 5).

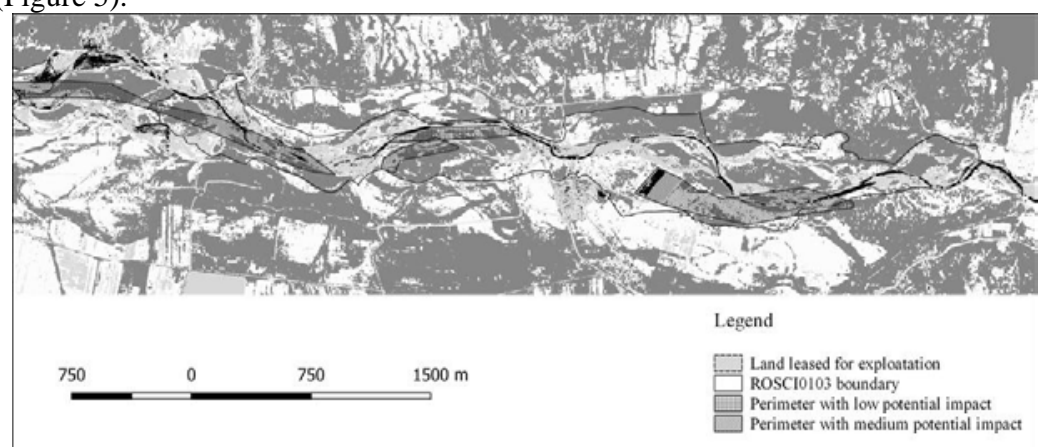

Figure 5. Potential impact rating classification 


\section{INTERNATIONAL SYMPOSIUM "THE ENVIRONMENT AND THE INDUSTRY", SIMI 2018, PROCEEDINGS BOOK}

Another objective of the analysis was to assess the pressure applied on the protection elements by the use of access roads servicing these perimeters. Based on the vector layer representing access roads and extracted from processing OpenStreetMap data, their total surface was identified, representing $0.43 \%$ from the surface of the protected area. The impact of these access roads which in most cases are improperly kept, is not generated by their surface, but because in many cases they are near or crossing forest areas (Figure 6).

Considering that the analysis was carried out on leased perimeters where the exploitation surfaces are constantly changing, we are of the opinion that as this activity continues, the share of access roads may significantly increase.

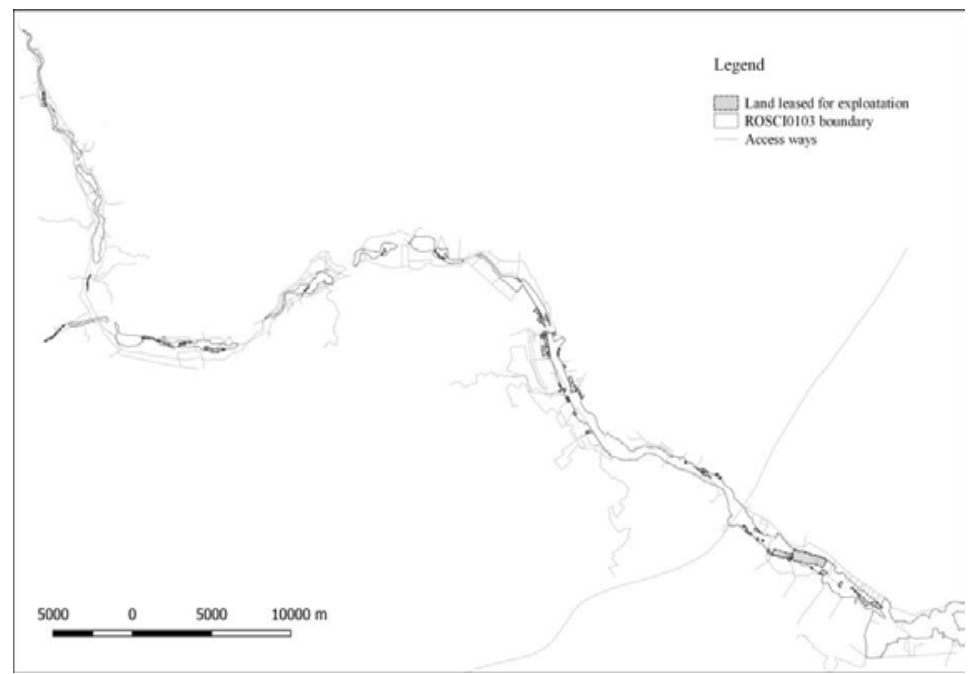

Figure 6. Access ways to gravel pits

\section{Results and Discussion}

The data processing in the framework of this study highlights how effective is the use of NDVI as a tool for assessing activities involving types of land management connected to the spatial distribution and the necessity to protect certain vegetation types. Besides the NDVI selectivity to the chlorophyll content and as a result for the analysis of various categories of vegetal associations or of their health, from the field calibration stage also resulted the index' sensitivity to highlighting other substrate types - alluvial sediments with variable humidity, water bodies or agricultural land with no vegetation (soil). 


\section{INTERNATIONAL SYMPOSIUM "THE ENVIRONMENT AND THE INDUSTRY", SIMI 2018, PROCEEDINGS BOOK}

The infrastructure elements generated by OpenStreetMaps data sets were very useful in analyzing the impact generated by the exploitation of alluvial material. These data allow for an accurate evaluation of the pressure applied by this economic activity on species and habitats of community interest.

By considering how the vegetal associations are impacted and the risk for accentuating the erosion processes, it resulted that around 30\% from the leased surfaces located inside the protected area, were included in the second class, corresponding to areas with significant potential impact.

\section{Conclusions}

Following the assessment, maps were drawn up highlighting the details of exploitations, the risk elements associated with the spatial-temporal evolution.

These are the key elements in the process of assessing the environmental impact and the risk for the population in affected areas.

It is not possible to approach the issue of protected areas management, correlated with the impact generated by the economic activities carried out in these perimeters, without the use of appropriate tools to manage environmental data, spatial analysis and development scenarios.

Although the Romanian legal framework clearly addresses these potential risks, abandoned borrow pits are still a major environmental problem, fact that indicates a lack of proper technical expertise, unsustainable engineering practice and insufficient law enforcement.

\section{Acknowledgements}

Sectoral Operational Program Environment 2007-2013, Priority Axis 4 Implementation of Adequate Management System for Nature Protection.

\section{References}

Formularul standard Natura 2000, Available from: Ministry of Environment, http://www.mmediu.ro/app/webroot/uploads/files/2016_02_26_SDF_Natura\% 202000_SPA_022016.pdf, pp. 790-797. [26 February 2016].

Omran, EE 2012, 'Detection of Land-Use and Surface Temperature Change at Different Resolutions', Journal of Geographic Information System, vol. 4, no. 3, pp. 199.

Online maps: https://www.openstreetmap.org/\#map=12/45.4247/27.7827 [02 August 2018]

Yengoh, GT, Olsson, DDL, Tengberg, Anna E \&Tucker III, CJ 2015, Use of the Normalized Difference Vegetation Index (NDVI) to Assess Land Degradation at Multiple Scales, Springer, London, pp. 17-18. 